\title{
The Evaluation of City's Low-carbon Development Based on the Fuzzy Analytical Hierarchy Process
}

\author{
Jinzhao An \\ School of Management, Northwest University for Nationalities, Lanzhou, P.R. China, \\ anjinzhao6@163.com
}

Keywords: Fuzzy synthetically evaluation; Low carbon city; Index system.

\begin{abstract}
First, we analyze the low carbon city's evaluation index systems in the relative researches, and utilize the analytical hierarchy process to study the factors of low carbon city development. The evaluation index system's first grade indicator is composed of five indicators. They are energy saving, emission reduction, economic development, resource carrying capacity, and living quality. The content of these first grade indicators is analyzed in details. Then the evaluation index system of low carbon city is built. At last, the weighting factors of the first grade indicators are got by analytical hierarchy process, the evaluation matrixes are got by fuzzy mathematical method, and then the synthetically evaluation model is established by the weighting factors and the evaluation matrixes. This paper provides a good way to optimize the low carbon city development decision with quantitative and qualitative research means.
\end{abstract}

\section{Introduction}

Low carbon city is a new urban form, which could improve the living quality and city's development. And the harmony between human and nature could be realized during the construction of low carbon city. Ecological civilization is a civilization form based on highly developed industrial civilization with industrialization and urbanization, and it values the climate and resource environment during city development. During the development of city, low carbon city construction could provide a new development pattern which could accomplish industrialization and urbanization constrained by resource environment. It could improve the living quality and urban competitiveness when seek the city's value maximization. The new city development pattern is a process of transition from industrial civilization to ecological civilization. So it is more important to evaluate the low carbon city construction process than the construction result.

The global climate change become seriously, and the low carbon city construction has become the regions' practice from theoretical discussion. The game playing of carbon emission has become more intense between the countries. So it is important to confirm the concept of low carbon city and to study the quantitative evaluation of the low carbon city construction.

\section{The Characteristic of Low Carbon City Construction}

According to the construction of low carbon city around the world, the concept of low carbon city blends the low carbon economy, sustainable development, ecological city, cyclic economy, and green development. It consists these development concepts during the developing process of the city, and has strong integration force to ensure the operability.

Low Carbon Economy. The concept of low carbon city is an evolution from the concept of low carbon economy. The low carbon economy is the base of low carbon city. The climate deterioration is environment problem, and also development issue. Ultimately, the development pattern is the key issue.

The low carbon economy depends on technology leapfrogging and institutional constraint to improve the energy efficiency, energy structure, consuming behavior rationality, and social economic development level.

Low carbon economy is an economic form with a certain level of carbon productivity and human development. It is aimed at the realization of the shared vision to control the greenhouse gas 
emission. The carbon productivity is GDP output of unite $\mathrm{CO}_{2}$ emission, and its improvement means more social wealth with less consumption of material and energy. Human development means the economy moves with health, education, ecological protection, and social equality.

Ecological City. The low carbon city is closely connected to ecological city in theory. In essence, both of them chase the harmonious between human and nature. They see the economy, society, culture, and environment as an ecological system. And they want to get a containable development pattern with the advance of human and nature.

Sustainable Development. The economic growth alone ignores the community organization, political institution, and culture, and causes development dilemma. The human-centered development view ignores the harmonious development of society and natural environment, and causes serious ecological issue. The sustainable development view's core side includes comprehensive outlook on development, ecological outlook on development, and equal outlook on development. The sustainable development view combines society, technology, culture, and environment as a whole. The human should respect for nature, leaning from nature, and protect nature. The economy and society's development shouldn't surpass the carrying capacity of resource and environment. And the view emphasizes the equity. The development of some people shouldn't damage the other people's benefit. The development shouldn't damage the development opportunity of future generations.

In a word, the natural ecosystem should be protected, and the natural resource should be utilized efficiently. Cyclic utilization of resource should be adopted. The productive process and consumption pattern should be low carbon and ecological. The low carbon city's development pattern is sustainable pattern with the development of economy and living quality.

\section{Evaluation Index System of Low Carbon City}

Building the evaluation index system of low carbon city should consider the ecological civilization and translation of urban development pattern. And should regard industrialization, urbanization, quality of urban development as key points. At last, the index system should be operable for low carbon city construction.

According to the analysis of low carbon city's key factors, this research divide the evaluation indicators of low carbon development into two grades. The first grade indicators include five. They are energy saving, emission reduction, economic development, resource carrying capacity, and living quality. And every of the first grade indicators include some second grade indicators. This research would study these indicators and design an efficiency evaluation system to evaluate the city's low carbon development.

Energy Saving Indicators. The energy saving indicators are divided into two types, energy efficiency and energy structure. Energy efficiency indicators include energy consumption per 10,000 yuan of GDP, energy consumption per unite of industrial added value, electricity consumption per unite of GDP, energy consumption of unite output value, and efficiency of energy conversion. Energy structure indicators include total energy consumption, the proportion of coal consumption, and the proportion of electricity consumption.

Emission Reduction Indicators. The emission reduction indicators are divided into two types, environmental pollution and environmental improvement. The environmental pollution indicators include $\mathrm{CO} 2$ emission per unite of GDP, and the three wastes emission per unite of GDP. The environmental improvement indicators include domestic waste processing rate, water use per capita, the multipurpose utilization rate of industrial solid wastes, and participation of low carbon lifestyle.

Economic Sustaining Indicators Per Capita GDP. The economic sustaining indicators could examine the economic supporting capacity of low carbon city construction. It includes the tertiary industry added value's proportion of GDP, the research input's proportion of fiscal revenue, and urban residents' disposable income.

Resource Carrying Capacity Indicators. The resource carrying capacity indicators could examine the carbon sequestration capacity and resource endowment. It includes land development intensity, urban development land per capita, green coverage ratio, road area per capita, and 
ecological culture.

Living Quality Indicators. The living quality indicators examine urban civilization level and endogenous power of low carbon city construction. It includes Engel coefficient, per capita living space, air quality, and happiness index.

\section{The Evaluation Process}

Employing the above evaluating indicators system to evaluate the city $S_{1}$ 's low carbon city construction. Examining $S_{1}$ 's energy saving $\left(F_{1}\right)$, emission reduction $\left(F_{2}\right)$, economic sustaining $\left(F_{3}\right)$, resource carrying capacity $\left(\mathrm{F}_{4}\right)$, and living quality $\left(\mathrm{F}_{5}\right)$. The data of this paper is from the project experts' estimation. There are three similar cities as comparison object.

Table 1 The comparison of the four cities

\begin{tabular}{c|c|c|c|c}
\hline $\mathrm{F}_{i}$ & $\mathrm{~S}_{1}$ & $\mathrm{~S}_{2}$ & $\mathrm{~S}_{3}$ & $\mathrm{~S}_{4}$ \\
\hline $\begin{array}{c}\text { energy } \\
\left.\text { saving( } \mathrm{F}_{1}\right)\end{array}$ & 0.76 & 0.62 & 0.70 & 0.85 \\
\hline $\begin{array}{c}\text { emission } \\
\left.\text { reduction( } \mathrm{F}_{2}\right)\end{array}$ & 0.85 & 0.83 & 0.89 & 0.81 \\
\hline $\begin{array}{c}\text { economic } \\
\left.\text { sustaining( } \mathrm{F}_{3}\right)\end{array}$ & 0.91 & 0.84 & 0.82 & 0.76 \\
\hline $\begin{array}{c}\text { resource } \\
\text { carrying } \\
\left.\text { capacity( } \mathrm{F}_{4}\right)\end{array}$ & 0.87 & 0.81 & 0.81 & 0.92 \\
\hline $\begin{array}{c}\text { living } \\
\text { quality }\left(\mathrm{F}_{5}\right)\end{array}$ & 0.89 & 0.85 & 0.78 & 0.83 \\
\hline
\end{tabular}

According to Table 1, it is impossible to get scientific evaluation based on one of the five indicators. It is indispensable to carry out comprehensible evaluation of the city's low carbon development capacity.

Contrast the indicators $\mathrm{F}_{i}(\mathrm{i}=1-5)$ 's significance on the basis of the target layer to get the five indicators' weights. During the comparison process, the experts consider the comprehensive factors, and get the judgment matrix R.

In a similar way, contrast the $\mathrm{S}_{i}(\mathrm{i}=1-4)$ on the basis of $\mathrm{F}_{i}(\mathrm{i}=1-5)$, and get the judgment matrixes $\mathrm{F}_{i}(\mathrm{i}=1-5)$. And then calculate the weights of the criterion layer, and the comparison feature vectors.

Every column of the judgment matrix $\mathrm{R}$ is be normalized by the standard column average way. Then get the normalized judgment matrix $\mathrm{R}$ '.

Then calculate the averages of every range of the R'. And get the five indicators' weight RW.

Similarly, process the judgment matrixes $\mathrm{F}_{i}(\mathrm{i}=1-5)$ by the standard column average way. Then get the cities' comparison feature vectors. And these vectors form the comparison matrix FW of the five indicators.

FW multiply by RW. Then get the synthesis core of the four cities on the basis of the five indicators. And get the comprehensive ranking of the four cities' low carbon construction.

\section{Conclusion}

The evaluation of the city's low carbon development is complex. The related theory and method need be studied further. In this paper, the factors of low carbon city's development are be analyzed. Construct the evaluation indicators system of the low carbon development. And employ the fuzzy evaluation method and the analytic hierarchy process method to study the evaluation process of low 
carbon development. The research provides a feasible way to evaluate the city's low carbon development.

\section{References}

[1] Wang Xiaojie, Zhou Yingnan, Liu Huanhuan. Research on the Forecasting Model of Energy-saving Potentials in Industry Enterprises. China Population,Resources and Environment [J]. 2010, Vol.20, No.5, pp.27-30.

[2] TANG Yong-hong. Application of Performance Evaluation Matrix and Relativity Performance Matrix in CRM. China Market [J].2008(45), pp.10-12..

[3] Liao Hua, Wei YiMing. "China's Energy-Economic Development Stage and Energy Conversation Potential in the Long Run". Science \&Technology and Society [J]. 2012, Vol.27, No.2, pp.216-218.

[4] $\mathrm{Hu}$ Shuhua. Weighting Comprehensive Evaluation Method and Its Applications for Product Design Evaluation. China Mechanical Engineering [J].1993 (11), pp.26-29.

[5] Richard G.Newell, AdamB.Jaffe, Robert N.Stavins.The effect of economic and policy incentives on carbon mitigation technologies [J], Energy Economics, 2006.11.563-578.

[6] Wang Yafei, Zheng Minghui. "Allocation of Energy Consumption among Provinces in China and Energy Saving Analysis", Guizhou Agricultural Science [J]. 2012, Vol.40, No.5, pp.195-200.

[7] Wang Mingjie,Li Yuling, Yang Li. "Analysis on Industrial Energy Saving Potential of Hebei in 12th Five-year Program". Journal of Shijiazhuang University of Economics [J]. 2011, Vol.34, No.1, pp.67-69.

[8] Wu Peilin,Wang Jianjun, Wang Hua. "Energy Conservation Potential Analysis in Compressed Air System for Industry Enterprises”. Compessor Technology [J]. 2012, No.1, pp.38-40.

[9] Qu Xiaoe. "Chinese Provincial Industrial Energy Efficiency and Energy Saving Potential: Empirical and Simulation-based DEA". Economic Management [J]. 2011, Vol.33, No.7, pp.16-24.

[10]Zheng Minghui, Wang Yafei. "Energy Consumption Provinces Configuration and Energy Saving Potential Analysis". Technology Economy \& Management Research [J]. 2012, No.4, pp.113-116. 